\title{
Alley section effects on blocking
}

\author{
E. J. CAPALDI, DONNA R. VERRY, and TIMOTHY M. NAWROCKI \\ Purdue University, West Lafayette, Indiana 47907
}

\begin{abstract}
The acquisition of discriminative stimulus control by brightness cues after prior discrimination training with hedonic cues produced by reward and nonreward in a successive go/no-go runway situation varied as a function of alley section. Blocking was substantial and perhaps complete in the start section, considerable in the run section, and entirely absent in the goal section. Explaining these findings has implications for understanding stimulus control in instrumental situations.
\end{abstract}

Hedonic memories, the internal cues produced by such events as food reward, nonreward, and shock, have been shown to powerfully control responding in a wide variety of instrumental learning situations (see, e.g., Capaldi, 1966, 1967; Capaldi \& Verry, 1981;Haggbloom, 1982; Seybert, Mellgren, Jobe, \& Eckert, 1974). Indeed, the powerful control exercised by hedonic memories in instrumental as opposed to classical tasks may be one of the major differences between the two situations (see, e.g., Neely \& Wagner, 1974). Hedonic cues have been found to be sufficiently salient both to overshadow brightness cues (Haggbloom \& Tillman, 1980) and to block control by brightness cues (Haggbloom, 1981; see also Haddad, Walkenbach, Preston, \& Strong, 1981). Haggbloom (1981) reported that blocking of brightness cues occurred in all alley sections of his differential conditioning apparatus, although, at least in the first of the two experiments reported, he indicated that the effect was most pronounced in the start section. The capacity of hedonic cues to block discriminative control by brightness cues in the start, run, and goal sections of a conventional brightness differential conditioning apparatus was examined in the investigation reported here.

A large unpainted box was placed beside a differential conditioning apparatus consisting of three runways in parallel (black, white, gray), each leading to a relatively small gray goalbox. In Phase 1 , rats in the blocking group were placed in the unpainted box, rewarded or nonrewarded, and then immediately transferred to the startbox of the gray runway, where they were rewarded in the goalbox of the apparatus following rewarded placements and nonrewarded following nonrewarded placements. This procedure produced discriminative responding in the gray runway. Under the procedure described, the relevant hedonic cues were those arising from rewarded and nonrewarded events in the placement box rather than from the goalbox of the apparatus, as in the Haggbloom investigations. In Phase 2, bright-

This research was supported by NSF Grant BNS 80-01171 to E. J. Capaldi. ness cues were made relevant along with the hedonic cues. In the test phase, placements in the unpainted box were discontinued and the amount learned by the blocking group about brightness cues relative to a control group trained with hedonic cues and brightness cues simultaneously relevant, but in the absence of prior experience with hedonic cues, was evaluated.

\section{METHOD}

\section{Subjects}

The subjects, 16 naive male rats, 77 days old on arrival at the laboratory, were purchased from the Holtzman Company, Madison, Wisconsin.

\section{Apparatus}

The apparatus consisted of three adjacent runways, identical except for brightness, one black, one gray, and one white. The gray startbox (21.6 cm long) and goalbox $(33.95 \mathrm{~cm}$ long) were on runners and could be positioned flush at the beginning and end, respectively, of any alley. Each alley was $190.8 \mathrm{~cm}$ long, $8.57 \mathrm{~cm}$ wide, and enclosed by $11.43-\mathrm{cm}$ sides covered by a top of wire mesh on a hinged frame. Lowering a brass startbox door started the first of three .01 -sec completely silent clocks. Start, run, and goal section times were recorded, starting and stopping of clocks being controlled by photobeams located $15.24 \mathrm{~cm}, 119.38 \mathrm{~cm}$, and $158.13 \mathrm{~cm}$ beyond the startbox door. Pellets, not visible from any point in the alley, were placed in a goal cup at the end of the alley. A brass door, painted gray on the goalbox door side, confined the rat to the goalbox. Beside the apparatus was a large, unpainted box $(28.76 \times 28.76 \times 28: 76 \mathrm{~cm})$ with a wire-mesh floor and hinged top. The box was placed on a stand and held a jar lid in which pellets were placed.

\section{Procedure}

Nine days after arrival at the laboratory, the rats were limited to $14 \mathrm{~g}$ of Wayne Lab Blox and handled daily, water being available on an ad-lib basis. Phase 1 , in which hedonic cues were relevant, began 10 days later, lasting to Day 28 . Each of two experimenters brought eight rats into the experimental room, four trained in Phase 1 (Group B, for blocking) and four not trained in Phase 1 (Group C, for control). Trials proceeded as follows. A rat was removed from the holding cage, placed in the unpainted box, given either 10.045 -g Noyes pellets or a 20 -sec nonrewarded confinement, and then, after eating the pellets or following $20 \mathrm{sec}$ on nonrewarded placements, immediately placed in the gray startbox, which in Phase 1 was always positioned before the gray alley. Following a rewarded placement, the rat was rewarded in the alley (10 pellets), and following a nonrewarded placement, the rat was nonrewarded in the alley 
(20-sec confinement). There were four such trials daily in Phase 1, except on Days 11-12, on which only two occurred: one rewarded and one nonrewarded trial. Rewarded and nonrewarded trials in Phase 1 occurred irregularly according to six different orders repeated every 6 days. Following a trial, the rat was placed in a holding cage and was given the next trial about 5-10 min later. Phase 2, beginning on Day 29, was run exactly as Phase 1 except that Group $C$ was now trained, rewarded placements were followed by a trial in one alley (black $S+$ for half the rats, white $S+$ for the other half), and nonrewarded placements were followed by a trial in the alley of the other brightness. In Phase 2, then, hedonic cues and brightness cues were simultaneously relevant for both groups. In Phase 3 , the test phase, which lasted 14 days, conditions were exactly as in Phase 2 except that placements in the box were discontinued, rats being taken from the holding cage directly to the runway. In Phase 3, then, only brightenss cues were relevant. In all phases, rats were given $180 \mathrm{sec}$ to enter the goalbox (60 sec assigned to each alley section) before placement in the goalbox. Subjects were fed the daily ration about $10 \mathrm{~min}$ after running was completed. A jar of Noyes pellets was placed beside the goalbox to control for potential food order cues arising from a baited vs. unbaited goal cup. Further, a cloth-lined cup was used to bait the goal cup to preclude auditory cues' signaling reward availability.

\section{RESULTS}

Discriminative responding, faster running on rewarded (S+) than on nonrewarded (S-) trials, developed in Phase 1. On the last 2 days of Phase 1, speeds (in centimeters per second) in Group B on S+ and S- trials, respectively, were, in the start section, 53.99 vs. 27.90 $[F(1,7)=34.36, p<.001]$, in the run section, 145.21 and $114.37[\mathrm{~F}(1,7)=11.08, \mathrm{p}<.02]$, and in the goal section, 109.19 vs. $81.32[\mathrm{~F}(1,7)=19.79, \mathrm{p}<.01]$. Figure 1 shows speeds in each alley section and in blocks of 2 days for Groups B and C on the last block of Phase 2 and each of the blocks of Phase 3 , the test phase. As Figure 1 shows, the groups differed little by the end of Phase 2, no difference between them even approaching significance. And both groups ran faster on St than on S- trials by the end of Phase 2 in each alley section [smallest $F(1,14)=47.18, p<.0001$, start section].

As Figure 1 and subsequent statistical analyses indicated, blocking in Phase 3 in Group B was virtually complete in the start section, substantial in the run section, and entirely absent in the goal section. Indicating most directly whether one group showed better discriminative responding than another are two interactions, Groups (B vs. C) by Trials (+ vs. - ) and Groups by Trials by Blocks. In the start section, we have for Groups by Trials, $F(1,14)=4.32(p<.053)$, and for Groups by Trials by Blocks, $F(6,84)=2.38(p<.05)$. In the run section, the Groups by Trials interaction was significant $[F(1,14)=5.48, p<.05]$, but not the Groups by Trials by Blocks interaction. In the goal section, neither the Groups by Trials nor the Groups by Trials by Blocks interaction was significant $(\mathrm{Fs}<1)$, indicating that the two groups discriminated equally well in that section. Subsequent Newman-Keuls tests

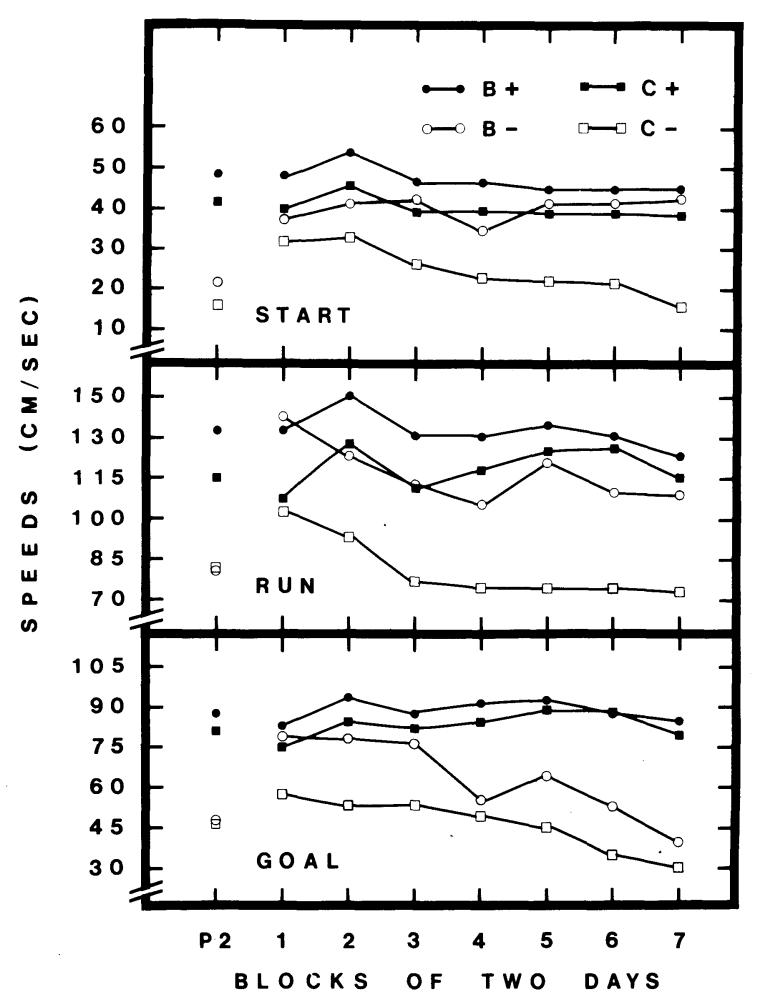

Figure 1. Speed of running in Groups $B$ and $C$ on $S+$ and $S-$ trials in each alley section on the last block of trials in Phase 2 (P2) and on each of the blocks of Phase 3, the test phase.

based on a breakdown of the Groups by Trials interaction indicated the following. In the start section, Group B did not run faster on S+ than on S-trials, but Group C did $(p<.05)$, and while the two groups did not not differ on $\mathrm{S}+$ trials, Group $\mathrm{C}$ ran more slowly than Group B on $\mathrm{S}-$ trials $(\mathrm{p}<.05)$. These results clearly indicate that in the start section in Group B, unlike in Group C, discriminative responding did not come under the control of brightness cues. Newman-Keuls tests in the run section indicated that both groups ran faster on $\mathrm{S}+$ than on $\mathrm{S}-$ trials $(\mathrm{ps}<.05)$ and that while the two groups did not differ significantly on $\mathrm{S}+$ trials, Group $\mathrm{C}$ ran more slowly than Group B on $S-$ trials $(p<.05)$. Of course, in the goal section, both groups discriminated in Phase 3 , running more rapidly on $\mathrm{S}+$ than on $\mathrm{S}-$ trials $(\mathrm{ps}<.05)$.

\section{DISCUSSION}

The acquisition of discriminative control by brightness cues after prior training with hedonic cues varied as a function of alley section. Blocking was substantial and perhaps complete in the start section, considerable in the run section, and entirely absent in the goal section. These findings suggest that from the start section to the goal section there was a progressive modification in hedonic and brightness cues. One possibility is that from the start to goal sections the hedonic cues, having been received some moments earlier, grew progressively less intense, with perhaps the brightness cues showing the opposite relationship.

Hall, Mackintosh, Goodall, and Dal Martello (1977) showed that a weak cue was not able to block subsequent control by a 
more intense cue. In the goal section here, then, weak hedonic cues may not have been able to block more intense brightness cues. Two possibilities exist in connection with the start section findings. In the start section, the hedonic cues may have been intense enough to block control by brightness cues. A second possibility recognizes that in Phase 2 , hedonic cues were informative some seconds before brightness cues. That is, following placements in the unpainted box, the animal was tranferred to the gray startbox, where, $3 \mathrm{sec}$ later, the startbox door was lowered to reveal the black and white alternative. Thus hedonic cues indicated whether reward or nonreward was to occur some seconds prior to brightness cues. Prior information by hedonic cues was also provided in Haggbloom's (1981) investigations. Haggbloom employed hedonic cues arising from the goalbox, rather than as here, from independent placements, and this may explain why he obtained blocking of brightness cues by hedonic cues in all alley sections when we did not.

As Mackintosh (1975) has indicated, most attention theories assume that subjects learn to attend not to a specific stimulus such as black alley or memory of reward, but to stimulus dimensions such as the brightness or hedonic dimensions. In the present investigation, brightness cues acquired control over responding in the goal section but not in the start section. This suggests, of course, that attention was directed not to stimulus dimensions, but to specific hedonic and brightness cues associated with each alley section. Indeed, it may be that brightness cues directly acquired control over responding only in the goal section here. Such control as was exercised by brightness cues in the run section may be due to generalization from the brightness cues of the goal section.

\section{REFERENCES}

Capaldi, E. J. Partial reinforcement: A hypothesis of sequential effects. Psychological Review, 1966, 73, 459-477.
Capaldi, E. J. A sequential hypothesis of instrumental learning. In K. W. Spence \& J. T. Spence (Eds.), The psychology of learning and motivation (Vol. 1). New York: Academic Press, 1967.

CAPAldi, E. J., \& Verry, D. R. Serial order anticipation learning in rats: Memory for multiple hedonic events and their order. Animal Learning \& Behavior, 1981, 9, 441-453.

Haddad, N. F., Walkenbach, J., Preston, M., \& Strong, R. Stimulus control in a simple instrumental task: The role of internal and external stimuli. Learning and Motivation, 1981, 12, 509-520.

Haggвloom, S. J. Blocking in successive differential conditioning: Prior acquisition of control by internal cues blocks the acquisition of control by brightness. Learning and Motivation, 1981, 12, 485-508.

HAGGBloom, S. J. Effect of N-R transitions during partial reinforcement pretraining on subsequent resistance to discrimination. Animal Learning \& Behavior, 1982, 10, 61-64.

Haggbloom, S. J., \& Tillman, D. J. Sequential effects on discrimination reversal. Learning and Motivation, 1980, 11, 318-338.

Hall, G. H., Mackintosh, N. J., Goodall, G., \& Dal Martello, M. Loss of control by a less valid or by a less salient stimulus compounded with a better predictor of reinforcement. Learning and Motivation, 1977, 8, 145-158.

Mackintosh, N. J. A theory of attention: Variations in the associability of stimuli with reinforcement. Psychological Review, 1975, 82, 276-298.

Neely, J. H., \& Wagner, A. H. Attenuation of blocking with shifts in reward: The involvement of schedule-generated cues. Journal of Experimental Psychology, 1974, 102, $751-763$.

Seybert, J. A., Mellaren, R. L., Jobe, J. B., \& Eckert, E. Sequential effects in discrete-trials instrumental escape conditioning. Journal of Experimental Psychology, 1974, 102, 473483.

(Received for publication May 7, 1982.) 